\title{
Impact of silk fibroin-based scaffold structures on human osteoblast MG63 cell attachment and proliferation
}

This article was published in the following Dove Press journal:

International Journal of Nanomedicine

I October 2015

Number of times this article has been viewed

\author{
Aneesia Varkey ${ }^{1,2}$ \\ Elakkiya Venugopal ${ }^{2}$ \\ Ponjanani Sugumaran ${ }^{2}$ \\ Gopinathan Janarthanan' \\ Mamatha M Pillai ${ }^{2}$ \\ Selvakumar Rajendran ${ }^{2}$ \\ Amitava Bhattacharyya' \\ 'Advanced Textile and Polymer \\ Research Laboratory, ${ }^{2} \mathrm{Tissue}$ \\ Engineering Laboratory, PSG Institute \\ of Advanced Studies, Coimbatore, \\ Tamil Nadu, India
}

\begin{abstract}
The present study was carried out to investigate the impact of various types of silk fibroin (SF) scaffolds on human osteoblast-like cell (MG63) attachment and proliferation. SF was isolated from Bombyx mori silk worm cocoons after degumming. Protein concentration in the degummed SF solution was estimated using Bradford method. Aqueous SF solution was used to fabricate three different types of scaffolds, viz, electrospun nanofiber mat, sponge, and porous film. The structures of the prepared scaffolds were characterized using optical microscopy and field emission scanning electron microscopy. The changes in the secondary structure of the proteins and the thermal behavior of the scaffolds were determined by Fourier transform infrared spectroscopy and thermo-gravimetric analysis, respectively. The biodegradation rate of scaffolds was determined by incubating the scaffolds in simulated body fluid for 4 weeks. MG63 cells were seeded on the scaffolds and their attachment and proliferation onto the scaffolds were studied. The MTT assay was carried out to deduce the toxicity of the developed scaffolds. All the scaffolds were found to be biocompatible. The amount of collagen produced by the osteoblast-like cells growing on different scaffolds was estimated.
\end{abstract}

Keywords: silk fibroin scaffold, electrospun nanofiber, porous film, sponge, osteoblast

\section{Introduction}

Regenerative medicine for bone repair and replacement is an important area of research. According to a US report, each year 1.3 million people undergo bone graft surgeries due to skeletal defects associated with accidents or diseases. ${ }^{1}$ One of the current treatments under practice is transplantation (either as autograft or allograft). There are various significant risks associated with this treatment approach, including second site damage, additional pain, longer healing time of the defective site, and conformal needs at the repair site. ${ }^{1,2}$ An alternative and widely practiced treatment method to replace diseased or damaged bone tissue is the application of a scaffold structure with a shape of interest. These scaffolds can be implanted either cell-free or pre-seeded in vitro with the patient's or donor's bone specific cells. In both cases, the cells are expected to differentiate and populate the entire scaffold and to resume the functions of the replaced tissue with time.

Different natural and synthetic biodegradable polymers are being used in tissue engineering of bone, including chitosan, hyaluronic acid, poly(L-lactide-coglycolide), polymethyl methacrylate, and poly- $\varepsilon$-caprolactone, as well as many ceramic materials like calcium sulfate, calcium phosphate, and bioactive glass. ${ }^{3-5}$ In addition to supporting qualities, such as mechanical properties, each of these materials possesses limitations in fulfilling the requirements for bone tissue engineering scaffolds.
Amitava Bhattacharyy

PSG Institute of Advanced Studies,

Peelamedu, Coimbatore 641004,

Tamil Nadu, India

Tel +91 9944920032

+91 422434 4000; Extn 4323

Email selvabiotech@gmail.com; amitbha1912@gmail.com submit your manuscript $\mid$ www.dovepress.com

Dovepress

http://dx.doi.org/10.2147/IJN.S82209
International Journal of Nanomedicine 20 I5: 10 (Suppl I: Challenges in biomaterials research) 43-5 I 43

cc) (i) (5) 2015 Varkey et al. This work is published by Dove Medical Press Limited, and licensed under Creative Commons Attribution - Non Commercial (unported, v3.0) License. The full terms of the license are available at http://creativecommons.org/licenses/by-nd/3.0/. Non-commercial uses of the work are permitted without any further permission from Dove Medical Press Limited, provided the work is properly attributed. Permissions beyond the scope of the License are administered by Dove Medical Press Limited. Information on how to request permission may be found at: http://www.dovepress.com/permissions.php 
The scaffold materials for bone tissue engineering should have proper morphology, biochemistry, and structure to promote adhesion, migration, and differentiation of osteoblasts and osteoprogenitor cells. The synthesis of new bone matrix with homogeneous distribution of cells in the scaffold avoids necrosis in the central regions where transport is more limited. ${ }^{6}$ In this scenario, silk fibroin (SF) can be exploited as an important class of biomaterial, as it has excellent biocompatibility, outstanding mechanical properties, low level of inflammatory response, and versatility in processing. ${ }^{7}$ Thus, silk has been considered as an ideal material for tissue engineering and biomedical applications. ${ }^{8}$ Natural silk fibers consist of two types of proteins, namely, fibroin and sericin. Fibroin is a hydrophobic protein that forms the filaments of silk, and sericin is a group of gummy hydrophilic proteins that bind the fibroin filaments together to form a cocoon. Silk displays remarkable toughness, strength, and compression resistance required for bone repair. ${ }^{9}$ Silk fibers obtained from Bombyx mori silk worms have been used as high-quality textile fibers and sutures for decades. ${ }^{10} \mathrm{SF}$ has been widely applied in regenerative medicine in different forms, including films, ${ }^{11}$ fibers, ${ }^{12}$ porous scaffolds, ${ }^{13}$ and microspheres. ${ }^{14}$ For the proper formation of bone tissue in the defective or diseased area, porous sponge scaffold fabricated from SF is more suitable as the pores in the scaffold can facilitate the attachment, proliferation, and migration of osteoblast cells. In addition, the transport of nutrients and waste into and out of the scaffold can be enhanced by its porosity. ${ }^{15}$ Porous silk sponges can be fabricated by using porogens, gas foaming, or lyophilization techniques. ${ }^{16} \mathrm{SF}$ nanofibrous scaffolds can be fabricated by electrospinning. It is a process by which fibers with nanometer-scale diameter can be fabricated from a solution containing SF by applying a high electric field. ${ }^{12}$ Films can be made from SF solution by the solution casting method. ${ }^{11}$ Silk along with RGD tripeptide exerts an anabolic effect on bone formation by acting as a receptor for the attachment of integrins present on the osteoblast cell membrane ${ }^{17}$ and increases osteogenic marker expression by suppressing the notch signaling pathway in mesenchymal stem cells. ${ }^{18}$

The purpose of this study was to understand the impact of structural morphology of various SF based scaffolds, such as nanofiber mats, sponges (lyophilized), and films, on human osteoblast-like cells (MG63), their attachment, growth, and proliferation. Biocompatibility, porosity, water retaining capacity, and biodegradability of these scaffolds were tested and analyzed for their suitability in tissue engineering. Cell viability of MG63 cells in scaffolds was deduced using the
MTT assay. The ability of osteoblast-like cells to secrete an extracellular matrix (ECM) was deduced by estimating the amount of collagen secreted into the medium.

\section{Materials and methods Materials}

B. mori silk worm cocoons collected from TANSILK, Coimbatore, India were used as the raw material for scaffold fabrication. Dulbecco's Modified Eagle's Medium (DMEM), fetal bovine serum (FBS), $\mathrm{Na}_{2} \mathrm{CO}_{3}, \mathrm{NaCl}, \mathrm{NaHCO}_{3}$, $\mathrm{MgSO}_{4} \cdot 7 \mathrm{H}_{2} \mathrm{O}, \mathrm{Na}_{2} \mathrm{HPO}_{4} \cdot 2 \mathrm{H}_{2} \mathrm{O}, \mathrm{MgCl}_{2} \cdot 6 \mathrm{H}_{2} \mathrm{O}$ (Himedia, Mumbai, India), calcium chloride $\left(\mathrm{CaCl}_{2} \cdot 2 \mathrm{H}_{2} \mathrm{O}\right)$ (Fisher Scientific, Mumbai, India), ethanol (99.9\%), Hoechst stain 33258, calf collagen, Sirius Red dye, chondroitin sulfate A sodium salt, 1,9-dimethylmethylene blue (DMMB), and trypsin (Sigma-Aldrich, St Louis, MO, USA) were used in this study. $\mathrm{CaCl}_{2}, \mathrm{KCl}, \mathrm{KOH}$, and $\mathrm{NaH}_{2} \mathrm{PO}_{4}$ were obtained from Merck (Mumbai, India). Dialysis membrane was purchased from Himedia (pore size $2.4 \mathrm{~nm}$, cut off 12-14 kDa). Human osteoblast-like cells used in this study were kindly donated by Dr C Sabarinathan, Department of Biotechnology, PSG College of Technology, Coimbatore, India.

\section{Extraction of SF from cocoon and purification}

SF was extracted from the cocoons according to modified protocols of Meechaisue et al. ${ }^{19}$ The cocoon was boiled for 30 minutes in $0.5 \%(\mathrm{w} / \mathrm{v}) \mathrm{Na}_{2} \mathrm{CO}_{3}$ solution to remove bound sericin. The process was repeated thrice by replacing the boiled solution with fresh $\mathrm{Na}_{2} \mathrm{CO}_{3}$ solution each time. Silk fibers degummed in this way were washed with copious amounts of distilled water and allowed to dry at $50^{\circ} \mathrm{C}$ in a hot-air oven overnight. Extracted SF was then dissolved in Ajisawa's reagent (containing $\mathrm{CaCl}_{2}$ : ethanol: water in a molar ratio of $1: 2: 8$ ) at $55^{\circ} \mathrm{C}$ for 4 hours with continuous stirring at $120 \mathrm{rpm}$. The dissolved SF solution was then dialyzed against ultrapure water with dialysis membrane for 3 days and concentrated using polyethylene glycol (PEG). Protein concentration in the dialyzed solution was estimated using Bradford method.

\section{Scaffold fabrication}

The purified SF aqueous solution was then processed to obtain different porous scaffolds, such as nanofibrous mats, sponges, and films using the same concentration of aqueous SF solution. Nanofibrous mats were prepared by electrospinning at optimized solution concentration (35\%), flow rate $(0.1 \mathrm{~mL} / \mathrm{h})$, voltage $(9 \mathrm{kV})$, needle tip and collector plate distance $(15 \mathrm{~cm})$, and needle diameter $(0.8 \mathrm{~mm})$. 
SF sponge was prepared by the lyophilization technique, ${ }^{20}$ and the porous film was fabricated by solution casting. ${ }^{11}$ All the scaffolds were treated with $90 \%$ methanol for 15 minutes in line with modified protocols of Jin et al. ${ }^{11}$

\section{Characterization of scaffold}

The morphology of the scaffolds was characterized using field emission scanning electron microscopy (FESEM) (Carl Zeiss, Germany). The scaffolds were dried at room temperature and gold coated before analysis. Fourier transform infrared spectroscopy (FTIR) spectra of pure and treated scaffolds were acquired over the wavenumber range of 4,000-400 $\mathrm{cm}^{-1}$ with ZnSe ATR cell (Shimadzu IR Affinity-1, Kyoto, Japan). The thermal behavior of treated SF scaffolds was analyzed using thermo-gravimetry (TG)/differential scanning calorimetry (DSC) (Netzsch, Selb, Germany). The temperature was raised from room temperature to $500^{\circ} \mathrm{C}$ at a heating rate of $10^{\circ} \mathrm{C} \mathrm{m^{-1 }}$ under nitrogen atmosphere. The porosity of scaffolds was calculated by the liquid displacement method using hexane as the displacement liquid. ${ }^{21}$ The surface pore size was measured using Image $J$ software from FESEM images. The structural integrity of the scaffold was tested in simulated body fluid (SBF). All three types of SF scaffolds were immersed in SBF ( $\mathrm{pH} 7.4$ ) in a 24-well plate and incubated at room temperature and observed for structural integrity under an inverted phase contrast epi-fluorescence microscope (Nikon Eclipse Ti-S series; Tokyo, Japan) for different time intervals.

\section{MTT assay}

The cell viability after growth in scaffolds was estimated using the MTT assay. Silk scaffolds of $2 \mathrm{~mm}$ size were placed in a 24-well plate and 10,000 cells/well were seeded onto it. After 4 days of incubation, the scaffolds were removed from the culture plate and used for the MTT assay in a 96-well plate. Twenty microliters of MTT was added to each well and incubated for 3.5 hours at $37^{\circ} \mathrm{C}$ in a culture hood. The media was removed carefully and $150 \mu \mathrm{L}$ of $4 \mathrm{mM} \mathrm{HCl}$ was added followed by agitation in an orbital shaker for $15 \mathrm{~min}$ utes. Optical density was read at $590 \mathrm{~nm}$ using a microplate reader (Multiskan GO; USA).

\section{Cell culture studies}

Scaffolds of known size were sterilized by immersing in 100\% ethanol for 6 hours followed by repeated washing in sterile distilled water and exposure to UV light for 2 hours. The cells were cultured in DMEM supplemented with 10\% FBS and incubated in a carbon dioxide $\left(\mathrm{CO}_{2}\right)$ incubator (Eppendorf,
Hamburg, Germany). Cells were allowed to reach $80 \%$ confluency and trypsinized for the study. Sterile scaffolds were placed in 24-well plates and inoculated with human osteoblast-like cells with a cell density of 10,000 cells/well. The attachment and morphology of the cells on the scaffolds were monitored by using an inverted phase contrast epi-fluorescence microscope and FESEM. Cell-seeded scaffolds were stained with Hoechst stain and observed under an inverted phase contrast epi-fluorescence microscope fitted with a filter having a wavelength of 460-490 nm. The images were captured using a Nikon CCD camera attached to the microscope.

\section{Nuclear staining}

Hoechst 33258 stain was used to visualize cell nucleus. Cells were prewashed with phosphate-buffered saline (PBS) solution and incubated for 10 minutes in room temperature after adding Carnoy's fixative (acetic acid: methanol, 1:3). Further, cells were treated with Hoechst 33258 stain and incubated for 30 minutes. Cells were monitored for fluorescence using the inverted phase contrast epi-fluorescence microscope.

\section{Estimation of collagen}

The collagen secreted by the cells in the ECM was estimated at regular time intervals. The medium taken from the scaffolds without cells was used as blank. The extracellular collagen content in the medium was estimated using Sirius Red dye according to the modified Tullberg-Reinert and Jundt method. ${ }^{22}$ A known concentration of Sirius Red dye prepared in $0.5 \mathrm{M}$ acetic acid solution was added to a known quantity of medium from the cell culture plates and mixed well for 5 seconds. The plates were incubated undisturbed for 30 minutes. The samples were centrifuged at 1,500 rpm for 10 minutes and the pellet was washed with $0.01 \mathrm{~N} \mathrm{HCl}$ to remove the unbound dye. The pellet was resuspended in $0.1 \mathrm{~N} \mathrm{KOH}$ and absorbance was measured at $540 \mathrm{~nm}$ using a microplate reader. Calf collagen was used as standard.

\section{Statistical analysis}

All experiments were performed in triplicate and data were expressed as mean \pm standard deviation. Statistical analysis was carried out using Origin Pro8.0 software. One-way ANOVA with Tukey's multiple comparison tests were used to analyze MTT assay and collagen estimation $(P \leq 0.05)$.

\section{Results and discussion Scaffold fabrication and characterization}

The dialyzed SF was used for the preparation of three different scaffolds, namely, nanofibrous mats, sponges, and films. 
The amount of total protein in the partially purified SF solution was found to be $2.0 \mathrm{~g} / 100 \mathrm{~mL}$. All the three scaffolds were prepared using suitable techniques as mentioned earlier. The advantage of our process over other reported processes is the use of aqueous SF solution for scaffold preparation instead of caustic solvents. The use of aqueous phase with SF proteins will lead to complete degradation of silk matrix by protease over time that is unlikely when dissolved in organic solvents. ${ }^{23}$ The morphology and diameter of the scaffolds were calculated from FESEM images. The FESEM images of the nanofiber, sponge, and film revealed the porous nature of all the scaffolds. The silk nanofibers had an average fiber diameter of $400 \pm 100 \mathrm{~nm}$ (Figure 1A). The minimum and maximum nanofiber diameter was found to be $100 \mathrm{~nm}$ and $600 \mathrm{~nm}$, respectively. The sponge-type scaffold showed the presence of large interconnected pores $(35 \pm 17 \mu \mathrm{m})$ (Figure $1 \mathrm{~B})$. The nanofibrous mats had the smallest pore diameter $(0.25 \pm 0.053 \mu \mathrm{m})$ (Figure 1A) when compared to all the scaffolds. The film diameter was found to be $0.35 \pm 0.10 \mu \mathrm{m}$ (Figure 1C). The surface functional groups of the scaffolds were deduced using FTIR analysis (Figure 2). The presence of methanol on different scaffolds fabricated from SF, as well as pure and treated scaffolds were also analyzed by FTIR. In the spectrum of pure SF nanofiber (Figure 2A), the band for amide I was observed at $1,643 \mathrm{~cm}^{-1}(\mathrm{C}=\mathrm{O}$ stretching), amide II at $1,527 \mathrm{~cm}^{-1}$ (N-H deformation), and amide III at $1,234.44 \mathrm{~cm}^{-1}$ (C-N stretching, $\mathrm{C}=\mathrm{O}$ bending vibration). These results indicate a random coil/silk I conformation. ${ }^{14-16}$ The result of methanol-treated SF nanofiber was obtained by comparing the spectra of pure and treated SF nanofibers (Figure 2A), where there is a shifting of band $1,643 \mathrm{~cm}^{-1}$ (amide I) in pure SF to $1,519 \mathrm{~cm}^{-1}$ (amide II) in treated SF. SF sponge (Figure 2B) and SF film (Figure 2C) show the
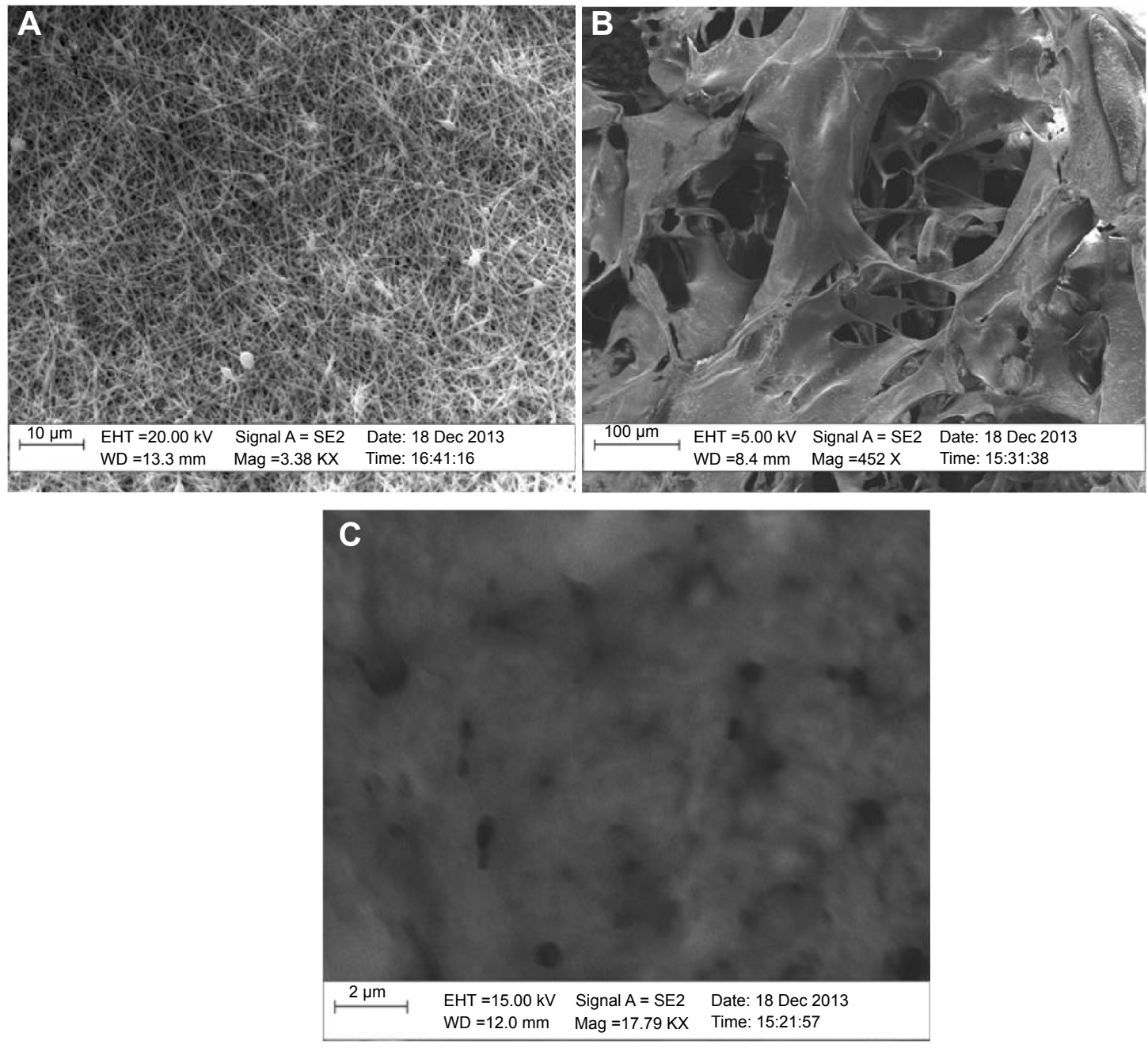

Figure I SEM images of SF scaffolds - electrospun nanofibrous scaffold (A), lyophilized sponge (B), and solvent casted film (C). Abbreviations: SEM, scanning electron microscopy; SF, silk fibroin. 

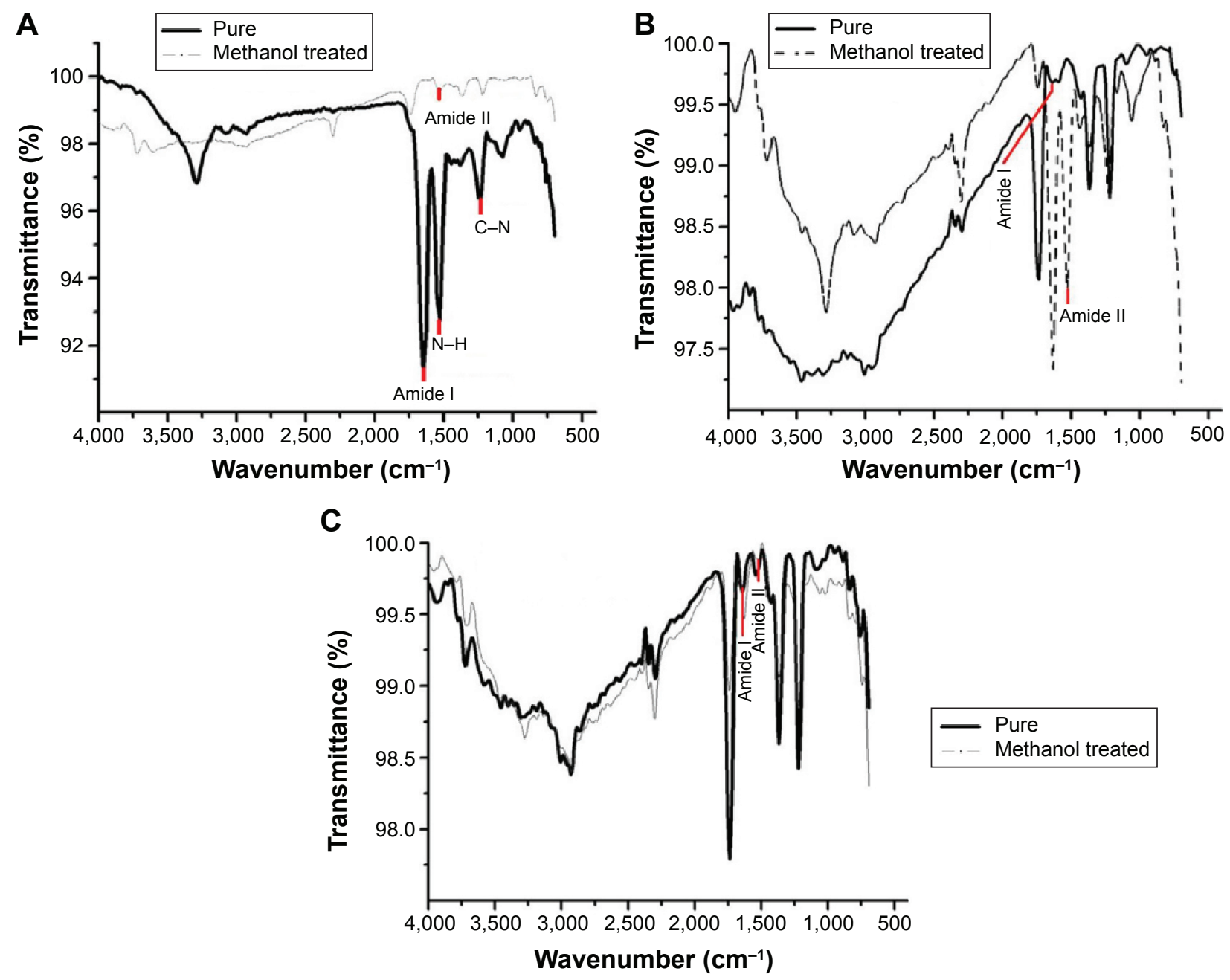

Figure 2 FTIR absorbance spectra of SF scaffolds with and without methanol-treated electrospun nanofibrous scaffold (A), lyophilized sponge (B), and solvent-casted film (C). Abbreviations: FTIR, Fourier transform infrared spectroscopy; SF, silk fibroin.

wavenumber shift corresponding to conformational change between pure and treated SFs. ${ }^{24-26}$ After methanol treatment, SF molecules present in the scaffold can structurally rearrange themselves due to the variations in hydrogen bonding, resulting in $\beta$-sheet conformational change. ${ }^{21}$ Thermo-gravimetric analyses of the treated SF nanofiber, sponge, and film are shown in Figure 3. In the case of each scaffold, there is an exothermic peak at $275^{\circ} \mathrm{C}$ that may be due to the crystallization of protein molecules as a result of methanol treatment. The TG curve of SF is also characterized by an intense endothermic peak at $284^{\circ} \mathrm{C}\left(T_{\mathrm{d}}\right)$ related to the decomposition of SF chains. ${ }^{25-27}$ The porosity of the scaffold was estimated using the liquid displacement method. The porosity was high in the case of sponge (67\%), followed by nanofiber (49\%) and thin films (33\%). Since porosity supports better cell growth by facilitating nutrition as well as excretion of wastes, it is necessary that the scaffolds are porous enough. The degradation behavior of SF scaffolds treated with methanol was determined by analyzing the structural integrity of the scaffolds microscopically. Scaffolds incubated in SBF solution were analyzed at different periods of time (figure not shown). The structural integrity of the treated nanofibrous mat was lost after 4 weeks of incubation in SBF. However, in the case of sponge and film, the structural integrity was intact even after 4 weeks of incubation in SBF. The delay in the biodegradation process may be attributed to the crystallinity or the methanol treatment of scaffolds. This identified structural loss in the nanofiber scaffold may be due to degradation of small hydrolytic peptide sequences that remain even after scaffold crystallization. ${ }^{28}$

\section{MTT assay}

The response and cytotoxicity of various silk scaffolds on MG63 osteoblast-like cells was investigated by the MTT assay. The MTT assay is based on the reduction of 


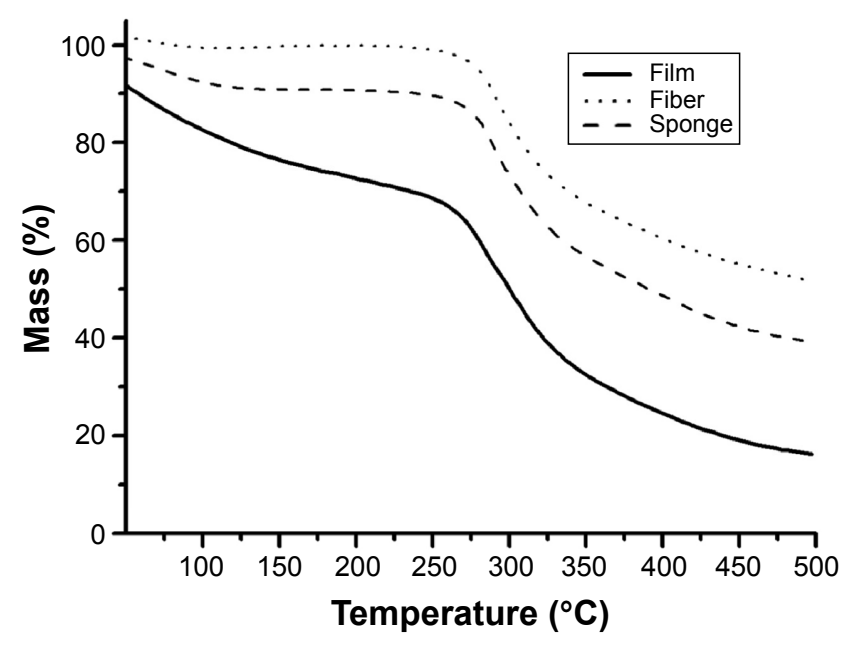

Figure 3 TGA curve of methanol treated SF scaffolds.

Abbreviations: TGA, thermo-gravimetric analysis; SF, silk fibroin.

the yellow tetrazolium salt to purple formazan crystals by dehydrogenase enzymes secreted from the mitochondria of metabolically active cells. The amount of purple formazan crystals formed is proportional to the number of viable cells. ${ }^{29} \mathrm{~A}$ known concentration of cells was seeded onto silk scaffolds. Figure 4 clearly indicates that the SF-based scaffold did not have any toxic effect on the osteoblast-like cells, but in turn, a few scaffolds increased the viability of cells. However, the percentage viability of the cells in scaffolds and in control was at the same level of statistical significance. These results clearly indicate that SF-based scaffolds prepared using aqueous solution are totally nontoxic to osteoblast-like cells and the scaffolds do not show any adverse effect on the growth of cells. Hence, these scaffolds can be considered suitable for bone tissue engineering.

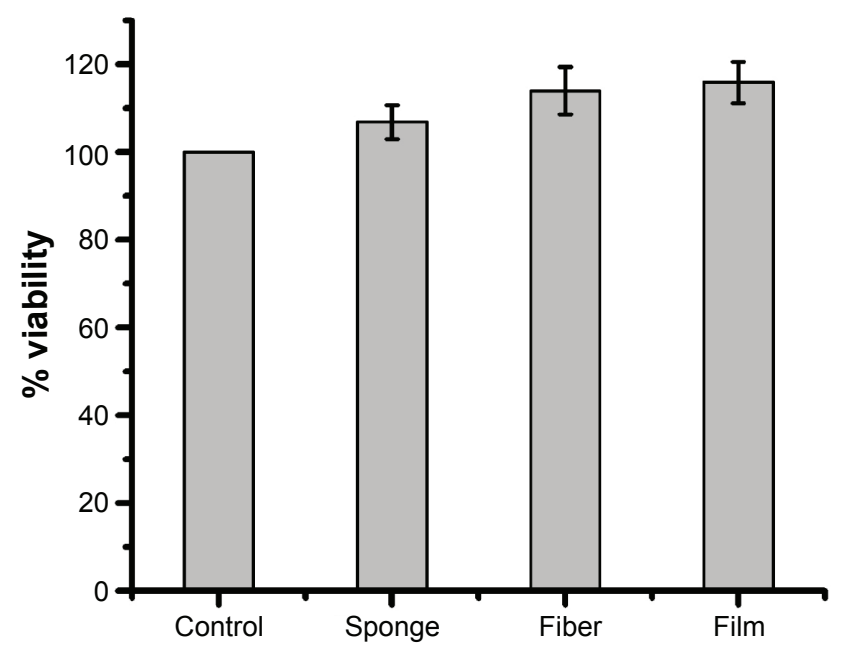

Figure 4 MTT assay for various SF scaffolds with osteoblast-like cells. Abbreviation: SF, silk fibroin.

\section{Cell culture studies}

The cytocompatibility of the scaffolds was studied in vitro by seeding osteoblast-like cells onto the methanol-treated scaffolds in DMEM. The attachment and morphology of the cells on the scaffold were observed each day under an inverted phase contrast microscope. As an evidence of the capacity of scaffolds to support cell attachment, it was observed that the majority of the cells started extending their cytoplasm over the surface of the scaffold after 5 days of cell seeding. The formation of filopodia was also observed. The number of cells on the scaffold surface was found to increase with the increase in incubation time. After 15 days (fixed based on a preliminary study for optimum cell attachment) of cell seeding, the scaffolds were air dried and observed under inverted phase contrast microscope and FESEM. Scaffolds with varying porosities promote osteoblast-like cell attachment and proliferation as reported earlier. ${ }^{30}$ In this study, the proliferation of cells inside the scaffold was not observed in the case of SF films and nanofiber, whereas in sponge, attached cells were observed inside the pores (Figure 5). Less penetration of cells onto nanofibrous mat and thin film scaffolds may be attributed to the smaller pore size. ${ }^{19}$ Nanofibrous scaffolds showed a monolayer of cells. However, sponge scaffolds showed individual osteoblast attachment and proliferation that may be attributed to the high interconnectivity of pores. ${ }^{25}$ The attachment and proliferation of cells on various scaffolds were also visualized using nuclear staining (Hoechst staining). These images of stained nuclei indicated the attachment and proliferation of cells on the scaffold surface and their viability (Figure 6). The SF film and nanofibrous mat supported more cell attachment on the surface.

\section{Estimation of collagen}

Collagen content was found to increase with the number of days. The amount of collagen estimated in control (cells without any scaffolds) and in scaffolds is illustrated in Figure 7. Initially, the rate of collagen secretion into the medium was high for all samples until 14 days, after which they reached saturation. Up to the 12th day, there was no significant difference in collagen secretion between control and cells on scaffolds. However, from the 14th day, the control showed significantly increased collagen secretion until the last day of analysis. At the end of 24 days, the control cells secreted $5.3 \pm 0.19 \mu \mathrm{g} / \mathrm{mL}$ of collagen. After 24 days of cell growth in various scaffolds, collagen content was found to be $3.3 \pm 0.51 \mu \mathrm{g} / \mathrm{mL}, 2.89 \pm 0.16 \mu \mathrm{g} / \mathrm{mL}$, and $3.5 \pm 0.2 \mu \mathrm{g} / \mathrm{mL}$ for the SF nanofiber, sponge, and film, respectively (Figure 7). The statistical analysis indicated little significance in the 

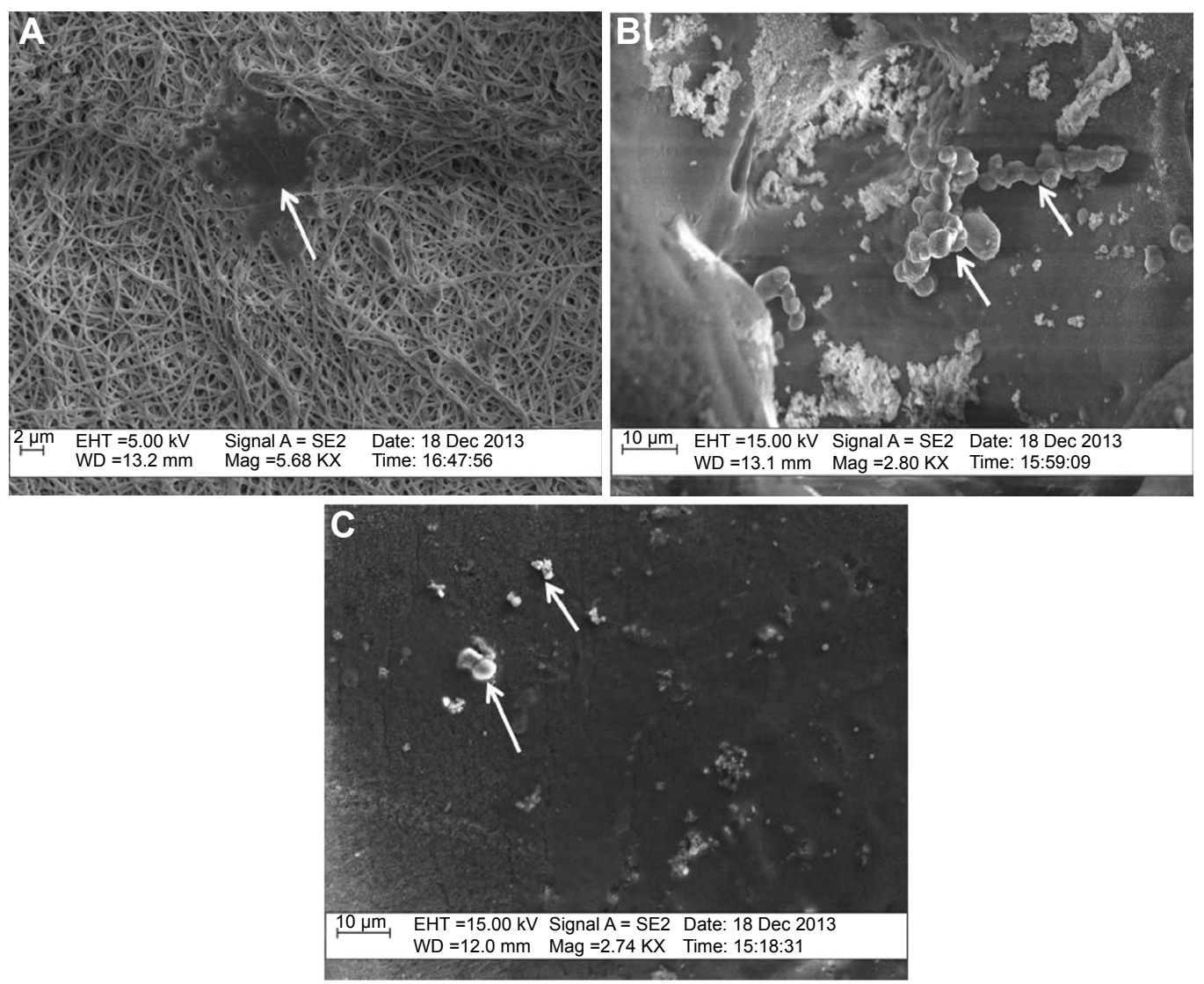

Figure 5 SEM images of osteoblast cells (MG63) attached to SF scaffolds - electrospun nanofibrous scaffold (A), lyophilized sponge (B), and solvent casted film (C). Note: Attached cells are indicated by arrows.

Abbreviations: SEM, scanning electron microscopy; SF, silk fibroin.
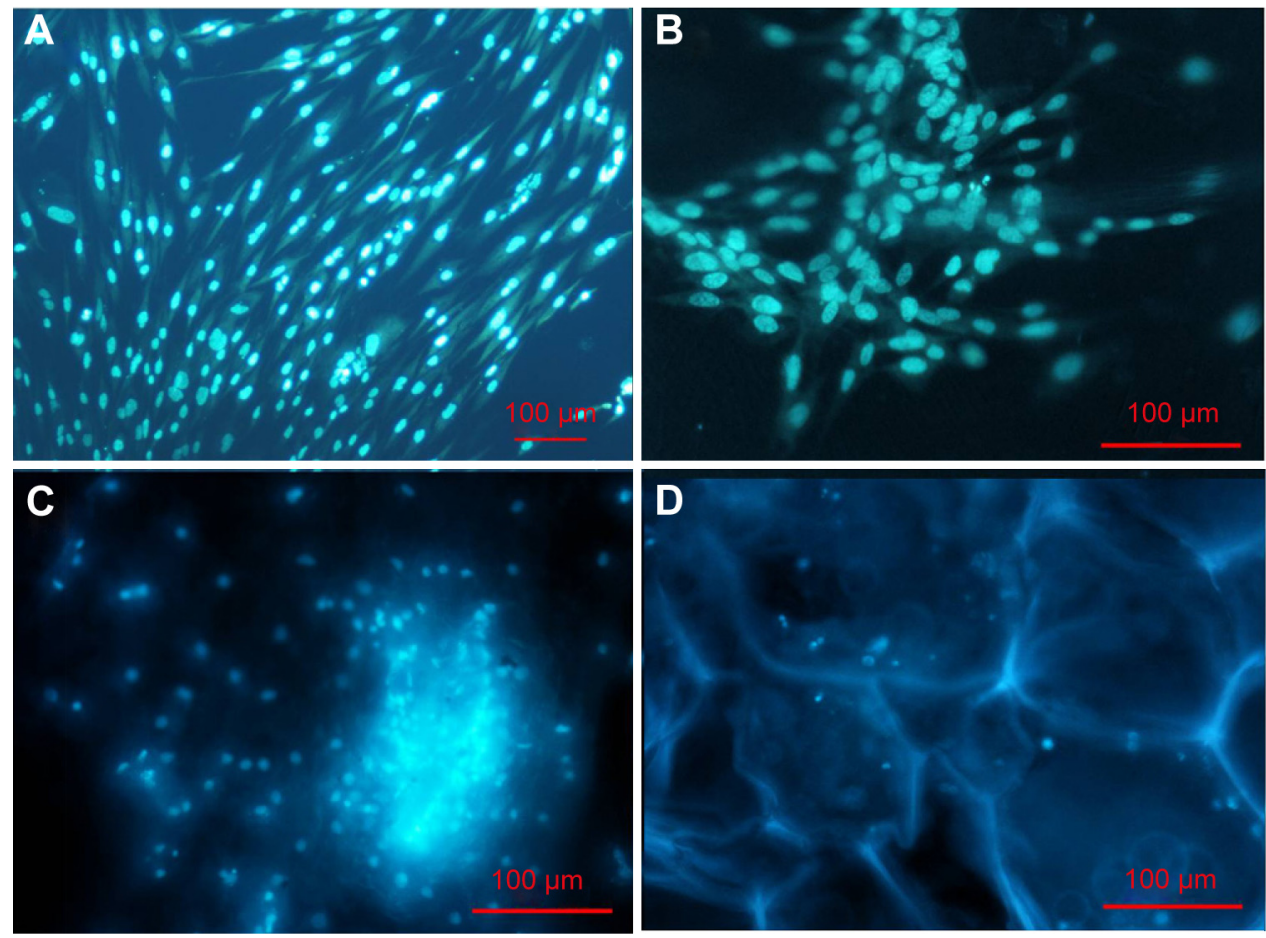

Figure 6 Hoechst stained images of osteoblast cells (MG63) control (A), cells attached to film (B), electrospun nanofibrous scaffold (C), and lyophilized sponge (D). 


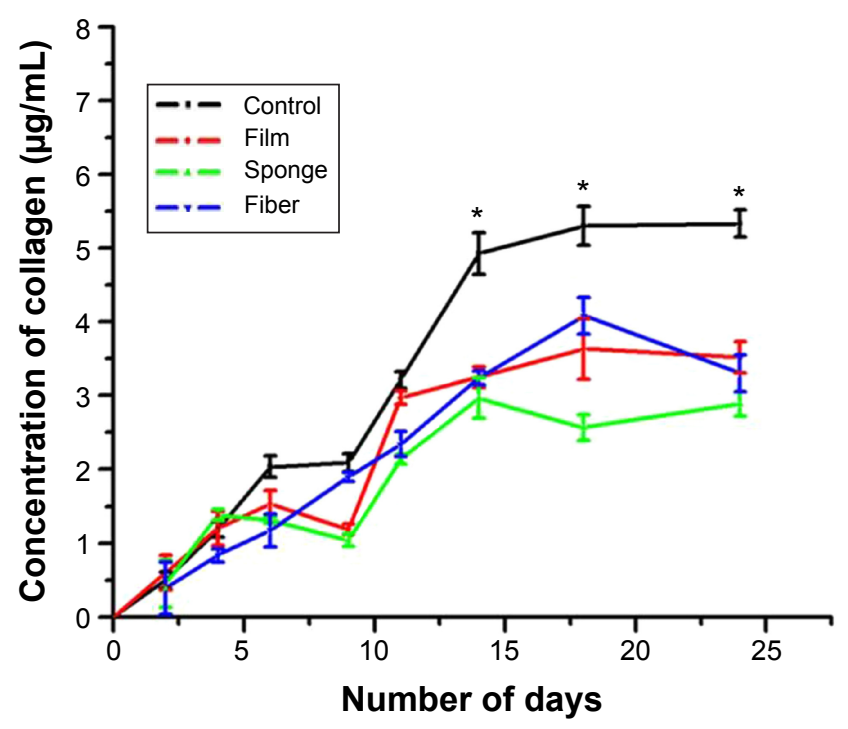

Figure 7 Amount of collagen secreted in culture media by osteoblast cells with and without scaffold (control).

Note: $* p<0.05$.

quantity of collagen secreted into the medium with respect to the SF scaffolds. This study clearly indicates that although the secretion of collagen by osteoblast-like cells in control was high beyond the 12th day, it varies slightly among the different types of SF scaffolds studied. The increase/decrease in collagen concentration directly provides the evidence of ECM production in the scaffolds by the cells.

\section{Conclusion}

SF-derived scaffolds were studied for the attachment and growth of osteoblast-like cells (MG63). Different types of porous scaffolds, such as the nanofiber, sponge, and film, were fabricated from an aqueous solution of SF protein isolated from B. mori cocoons. The porosity of scaffolds was found to be high in the sponge type of SF scaffolds when compared to films and nanofibers. When the scaffolds were incubated in SBF, the nanofibrous mat lost its structural integrity after 4 weeks, whereas the structural integrity was retained by sponge and film scaffolds. The SF film and nanofibrous mat supported more cell attachment. All the scaffolds were nontoxic to osteoblast-like cells. Hence, SF in various forms, including fibers, films, and sponges are promising scaffolds that can be exploited for the expansion of osteoblast-like cells for bone tissue engineering.

\section{Acknowledgment}

The authors wish to acknowledge the management, PSG Institute of Advanced Studies for providing facilities and sufficient funds to carry out this work. We would also like to thank Dr T Lazar Mathew, Advisor, and Professor P Radhakrishnan, Director, PSGIAS, for providing helpful comments and moral support throughout the study. We thank Johnson \& Johnson for sponsoring our paper for publication in this journal.

\section{Disclosure}

The authors declare no conflicts of interests, including direct or indirect financial relations, with any of the trademarks and companies mentioned in this paper.

\section{References}

1. Marquis ME, Lord E, Bergeron E, et al. Bone cells biomaterials interactions. Front Biosci. 2009;14:1023-1067.

2. Khan Y, Yaszemski MJ, Mikos AG, Laurencin CT. Tissue engineering of bone: material and matrix considerations. J Bone Joint Surg Am. 2008;90:36-42.

3. Dawson JI. Development of specific collagen scaffolds to support the osteogenic and chondrogenic differentiation of human bone marrow stromal cells. Biomaterials. 2008;29:3105-3116.

4. Wu X, Wang S. Regulating MC3T3-E1 cells on deformable poly ( $\varepsilon$-caprolactone) honeycomb films prepared using a surfactant-free breath figure method in a water-miscible solvent. ACS Appl Mater. Interfaces. 2012;4(9):4966-4975.

5. Wei J, Wu X, Liu C, et al. Fabrication of bioactive scaffold of poly (e-caprolactone) and nanofiber wollastonite composite. J Am Ceram Soc. 2009;92(5):1017-1023.

6. Ma PX, Zhang R, Xiao G, Franceschi R. Engineering new bone tissue in vitro on highly porous poly (a-hydroxy acids)/hydroxyapatite composite scaffolds. J Biomed Mater Res. 2001;54:284-293.

7. Wei K, Li Y, Kim KO, et al. Fabrication of nano-hydroxyapatite on electrospun silk fibroin nanofiber and their effects in osteoblastic behavior. J Biomed Mater Res A. 2011;97(3):272-280.

8. Altman GH, Diaz F, Jakuba C, et al. Silk based biomaterials. Biomaterials. 2003;24:401-416.

9. Jahanzeb C. Response of human osteoblasts to novel silk-based biomaterials, SoDM [Masters Thesis], Paper 2, 2006.

10. Pra ID, Freddi G, Minic J, Chiarini A, Armato U. De novo engineering of reticular connective tissue in vivo by silk fibroin nonwoven materials. Biomaterials. 2005;26:1987-1999.

11. Jin HJ, Park J, Valluzzi R, Cebe P, Kaplan DL. Biomaterial films of Bombyx mori silk fibroin with poly (ethylene oxide). Biomacromolecules. 2004;5(3):711-717.

12. Zhang X, Baughman CB, Kaplan DL. In vitro evaluation of electrospun silk fibroin scaffolds for vascular cell growth. Biomaterials. 2008;29(14):2217-2227.

13. Mandal BB, Kundu SC. Cell proliferation and migration in silk fibroin 3D scaffolds. Biomaterials. 2009;30(15):2956-2965.

14. Wang X, Wenk E, Matsumoto A, Meinel L, Li C, Kaplan DL. Silk microspheres for encapsulation and controlled release. J Control Release. 2007;117(3):360-370.

15. Marolt D, Augst A, Freed LE, et al. Bone and cartilage tissue constructs grown using human bone marrow stromal cells, silk scaffolds and rotating bioreactors. Biomaterials. 2006;27:6138-6149.

16. Vepari C, Kaplan DL. Silk as a biomaterial. Prog Polym Sci. 2007;32: 991-1007.

17. Sofia S, McCarthy MG, Gronowicz G, Kaplan DL. Functionalized silk-based biomaterials for bone formation. J Biomed Mater Res. 2001;54:139-148.

18. Jung SR, Song NJ, Yang DK, et al. Silk proteins stimulate osteoblast differentiation by suppressing the Notch signaling pathway in mesenchymal stem cells. Nutr Res. 2013;33(2):162-170. 
19. Meechaisue C, Wutticharoenmongkol P, Waraput R, et al. Preparation of electrospun silk fibroin fiber mats as bone scaffolds: a preliminary study. Biomed Mater. 2007;2:18.

20. Zhao Y, Legeros RZ, Jing Chen. Initial study on 3D porous silk fibroin scaffold: preparation and morphology. Bioceram Dev Appl. 2011;1:3.

21. Vasconcelos A, Gomes AC, Cavaco-Paulo A. Novel silk fibroin/elastin wound dressings. Acta Biomater. 2012;8:3049-3060.

22. Tullberg-Reinert H, Jundt G. In situ measurement of collagen synthesis by human bone cells with a Sirius red based colorimetric microassay: effects of transforming growth factor beta2 and ascorbic acid 2-phosphate. Histochem Cell Biol. 1999;112:271.

23. Kim UJ, Park J, Kim HJ, Wada M, Kaplan DL. Three-dimensional aqueous-derived biomaterial scaffolds from silk fibroin. Biomaterials. 2005;26:2775-2785.

24. Chen X, Shao Z, Marinkovic NS, Miller LM, Zhou P, Chance MR. Conformation transition kinetics of regenerated Bombyx mori silk fibroin membrane monitored by time-resolved FTIR spectroscopy. Biophys Chem. 2001;89:25-34.
25. Hu X, Kaplan DL, Cebe P. Determining beta-sheet crystallinity in fibrous proteins by thermal analysis and infrared spectroscopy. Macromolecules. 2006;39:6161-6170.

26. Chen X, Shao Z, Knight DP, Vollrath F. Conformation transition kinetics of Bombyx mori silk protein. Protein. 2007;68:223-231.

27. Hu X, Wang X, Rnjak J, Weiss AS, Kaplan DL. Biomaterials derived from silk-tropoelastin protein systems. Biomaterials. 2010;31: $8121-8131$

28. Lu S, Wang X, Lu Q, Hu X, Uppal N, Omenetto FG. Stabilization of enzymes in silk films. Biomacromolecules. 2009;10:1032-1042.

29. Ghasemi-Mobarakeh L, Morshed M, Karbalaie K, Fesharaki M, Hossein Nasr-Esfahani M, Baharvand H. Electrospun poly ( $\varepsilon$-caprolactone) nanofiber Mat as extracellular matrix. Yakhteh Med J. 2008;10(3):179-184.

30. Wu X, Wang S. Integration of photo-crosslinking and breath figures to fabricate biodegradable polymer substrates with tunable pores that regulate cellular behavior. Polymer. 2014;55:1756-1762.
International Journal of Nanomedicine

\section{Publish your work in this journal}

The International Journal of Nanomedicine is an international, peerreviewed journal focusing on the application of nanotechnology in diagnostics, therapeutics, and drug delivery systems throughout the biomedical field. This journal is indexed on PubMed Central, MedLine, CAS, SciSearch $®$, Current Contents $\AA /$ Clinical Medicine,

\section{Dovepress}

Journal Citation Reports/Science Edition, EMBase, Scopus and the Elsevier Bibliographic databases. The manuscript management system is completely online and includes a very quick and fair peer-review system, which is all easy to use. Visit http://www.dovepress.com/ testimonials.php to read real quotes from published authors. 